\title{
Glucose and Insulin Metabolism in Friedreich's Ataxia
}

\author{
D. SHAPCOTT, S. MELANCON, R. F. BUTTERWORTH, K. KHOURY, R. COLLU. \\ G. BRETON, G. GEOFFROY, B. LEMIEUX, AND A. BARBEAU
}

\begin{abstract}
SUMMARY: Our prospective survey of 50 ataxic patients confirms the previous finding of frequent clinical or chemical diabetes in Friedreich's ataxia. Eighteen percent of our typical cases have clinical diabetes and $40 \%$ at least an abnormal glucose tolerance curve. However, this finding does not appear to be specific to that form of ataxia. Furthermore, we have shown that most patients with at axia have normal or low fasting insulin levels, but a hyperinsulinic response to a glucose load.
\end{abstract}

RÉSUMÉ: Notre étude prospective de 50 patients ataxiques confirme les observations de la littérature quant à l'incidence de diabète "clinique" ou "chimique" dans l'ataxie de Friedreich. $18 \%$ de nos cas "typiques" ont un diabète clinique et près de $40 \%$, une courbe de tolérance au glucose anormale. Cependant, ce fait ne semble pas être spécifique à cette forme d'ataxie. Enfin, nous avons montré que la plupart des patients ataxiques ont des taux d'insuline à jê̂n normaux ou diminués ainsi qu' une réponse hyperinsulinique à une surcharge en glucose.

From the Centre Hospitalier Universitaire de Sherbrooke; the Hopital Ste-Justine, Montreal, the Clinical Research Institute of Montreal; and the Hôpital Hôtel-Dieu de Montreal.

Reprint requests for the complete supplement on Friedreich's ataxia to: Dr. André Barbeau, Clinical Research Institute of Montreal, 110 Pine Avenue West, H2W IR7 Montreal, Quebec, Canada.

\section{INTRODUCTION}

Numerous reports and several reviews have emphasized an increased incidence of diabetes mellitus in subjects suffering from Friedreich's ataxia. Earlier papers cited individual cases or cases appearing in siblings and, by 1940, Schlezinger and Goldstein had listed 20 cases of Friedreich's ataxia with diabetes. Ashby and Tweedy (1953) reported 2 cases occurring in sisters and cited 2 further cases for a total of 31 by 1953. Several reports of individual cases have since appeared (Podolsky et al., 1964; Joffe et al., 1970). Podolsky and Sheremata (1970) place this figure at 74 .

These earlier and individual cases may be summarized as showing that diabetes occurred more frequently in females with Friedreich's ataxia. It always followed overt clinical symptoms of ataxia. Apparently, diabetes was not found in the unaffected siblings of the ataxic subjects with diabetes. As Ashby and Tweedy (1953) observed, there was no clear indication as to whether the incidence of diabetes was greater in Friedreich's ataxia, than in the population at large and this could only be settled by a survey of an adequate number of cases of ataxia. Two such surveys have now been reported:

Thoren, in 1962, studied 50 cases of ataxia from 13 families and found 9 subjects with clinical diabetes and one prediabetic, giving an incidence of $20 \%$ as compared to $1.5 \%$ in the population at large. Only two of the cases of diabetes were siblings. Hewer and Robinson, in 1968, investigated 113 cases of ataxia and found 10 with clinical diabetes and a further 12 with impaired glucose to- lerance. The 10 cases of combined illnesses occurred in 9 sibships, totalling 24 cases of ataxia. Two of 30 non-ataxic sibs had diabetes. Because of the above findings, it was imperative to investigate in some detail the state of glucose metabolism in our 50 subjects.

\section{SUBJECTS AND METHODS}

The patients were selected from families with one or more cases of Friedreich's ataxia. Diagnostic criteria are described in a previous paper.

\section{Glucose tolerance test (G.T.T.)}

The subjects were given a high carbohydrate diet for 3 days preceeding the test. For the oral G.T.T., they received glucose $(1.75$ $\mathrm{g} / \mathrm{kg}$ body weight) and blood samples were collected at $0,30,60,90,120$ and 180 minutes or at $0,15,30,45$, $60,90,120,150$ and 180 minutes. For the intravenous G.T.T., the subjects received a bolus of $50 \%$ glucose solution $(0.5 \mathrm{~g} / \mathrm{kg}$ body weight $)$ and blood samples were collected at 0,5 , $10,20,30,45,60,90$ and 120 minutes. In a separate experiment, serum glucose levels were obtained fasting and 2 hours after a carbyhydrate rich meal. Serum glucose was measured by the Technicon Autoanalyzer and serum insulin by the double antibody radioimmunoassay. The glucose tolerance curves were evaluated according to the criteria of Danowsky (1957) and of Ikkos and Luft (1957). In the Danowsky evaluation, a score of 500 or above was considered abnormal.

\section{RESULTS}

The results of our studies of glucose and insulin metabolism can be 
TABLE I

Glucose and Insulin Metabolism

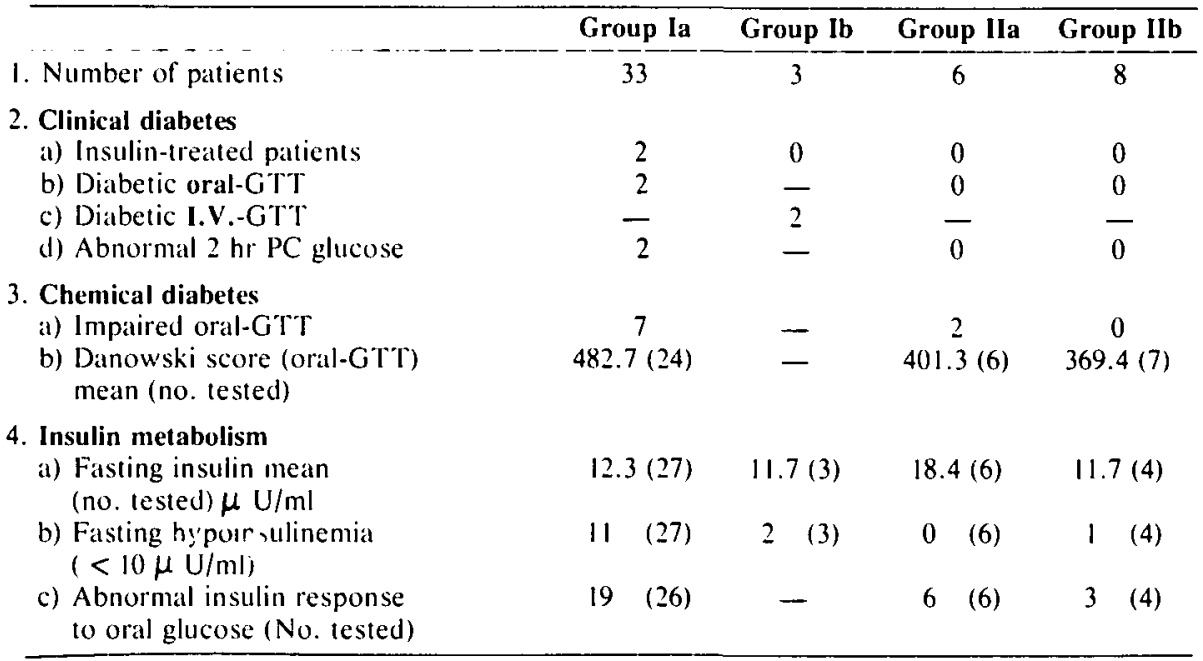

found in Table 1. In Group Ia (i.e., typical Friedreich's ataxia), there were 2 cases of insulin-treated known diabetes miellitus. A further 2 patients showed clearly diabetic oral glucose tolerance curves and 2 more, on whom the oral-GTT was not performed, had abnormally elevated $2 \mathrm{hr}$. P.C. blood glucose levels. Thus we can say that 6 patients with the typical form of the illness $(18.2 \%)$ have clinical diabetes. A further 7 patients had clearly impaired oral-GTT. These can be said to have chemical diabetes $(21.2 \%)$, for a total of $13 / 33$ patients $(39.4 \%)$ with diabetes. Of these, 9 were female, 4 male (in the total group 21 females; 12 males).

In the other clinical sub-groups, the proportion is much lower except in Group Ib (incomplete Friedreich's ataxia) where it is $66.7 \%$; in Group Ila (atypical recessive ataxia - possibly Roussy-Levy syndrome): no clinical diabetes and 2 impaired oral GTT; in Group IIa (mixed atypical ataxia): no clinical or chemical diabetes. These findings are confirmed by the Danowsky scores which are significantly higher (mean 482.7) in Group Ia than in the control ataxia cases, definitely not Friedreich's ataxia (Group IIb), where the mean was 369.4. Furthermore, in Group la, $54 \%$ of subjects had a score of 450 and higher as opposed to $0 \%$ in Group IIb, our ataxia control group.

The subjects with both ataxia and diabetes came from 13 families with a total of 57 sibs; none of the nonataxic sibs had diabetes. In only one case (No. 16, Group Ia), an insulintreated diabetic, was there a positive family history of diabetes on both maternal and paternal side.

Serum insulin levels were considered abnormal with fasting levels below $10 \mu \mathrm{U} / \mathrm{ml}$ and maximum insulin response to oral glucose administration below $70 \mu \mathrm{U} / \mathrm{ml}$ (hypoinsulinemia), or levels greater than $18 \mu \mathrm{U} / \mathrm{ml}$ fasting and greater than $100 \mu \mathrm{U} / \mathrm{ml}$ following a glucose ing levels are not significantly different between clinical sub-groups. However, there were 11/27 tested patients in Group Ia who had low fasting insulin levels $(40.7 \%)$, while this proportion is $66.7 \%, 0 \%$, and $25 \%$ for the other groups respectively. These figures are similar to the diabetic population identified above in each clinical sub-group, but the subjects involved are not necessarily identical. The same holds true for the abnormally high insulin responses $(>100 \mu \mathrm{U} / \mathrm{ml})$ in $19 / 26$ (73\%) of the patients from Group Ia, $6 / 6(100 \%)$ in Group IIa, and $3 / 4$ $(75 \%)$ in Group IIb. It is interesting to note that a hypersecretion of insulin has also been noted previously in ataxia telangiectasia (Schalch et al., 1970) and in 3 cases of Friedreich's ataxia (Joffe et al., 1970). Based on the insulin response to the glucose challenge (hyperinsulinemia). Fast- load, three groups of patients can clearly be delineated among those having both glucose and insulin responses measured at the same time (Figure 1). A type 1 insulin response (seen in 3 patients from Group Ia), which is a flat or low response is always accompanied by a classical diabetic glucose tolerance curve. A type 2 , or normal response, was seen in 3 other patients tested and was accompanied by a normal glucose tolerance curve. Finally, a type 3 , or "delayed" response was seen in 4 of the patients studied and was accompanied by a glucose tolerance curve similar to that in type 1 . A total of 27 insulin responses were calculated (14 with and 13 without simultaneous glucose measurements) in the total group of 50 patients. There were 8 type I responses, 5 Type II (normal) responses and 14 Type III.

\section{DISCUSSION}

Based on these results, it may be said that most patients with ataxia have some abnormality of insulin metabolism, whether or not they have clinical or chemical diabetes mellitus.

In the two previous large studies, Thoren (1962) found 10 cases out of 50 ataxia cases $(20 \%)$ with clinical diabetes while Hewer and Robinson (1968) found $9 / 113$ cases (8\%). Our own figure of $6 / 33$ (18.2\%) is similar to Thoren's. When impaired glucose tolerance curves are also assessed, Hewer and Robinson (1968), found the percentage of possible diabetics to be $20 \%$, while we find it to be nearly $40 \%$. However, as previously noted, it is dangerous to diagnose diabetes in severely crippled pratients because of the well known apparent glucose intolerance caused by immobility. In this respect, it should be stated that our Group IIb ataxic patients were certainly as physically handicapped as the Group Ia patients with typical Friedreich's ataxia, but none of them fell within the diabetic (clinical or chemical) group. Thus, whatever final figure we adopt for Friedreich's ataxia patients with diabetes $(8 \%, 20 \%, 40 \%)$, the proportion far exceeds what is found in the population at large 


\section{INSULIN AND BLOOD GLUCOSE RESPONSES IN FRIEDREICH'S ATAXIA TO GLUCOSE LOAD (ORAL)}

INSULIN $(\mu U / m I) \quad$ GLUCOSE (mg \%)
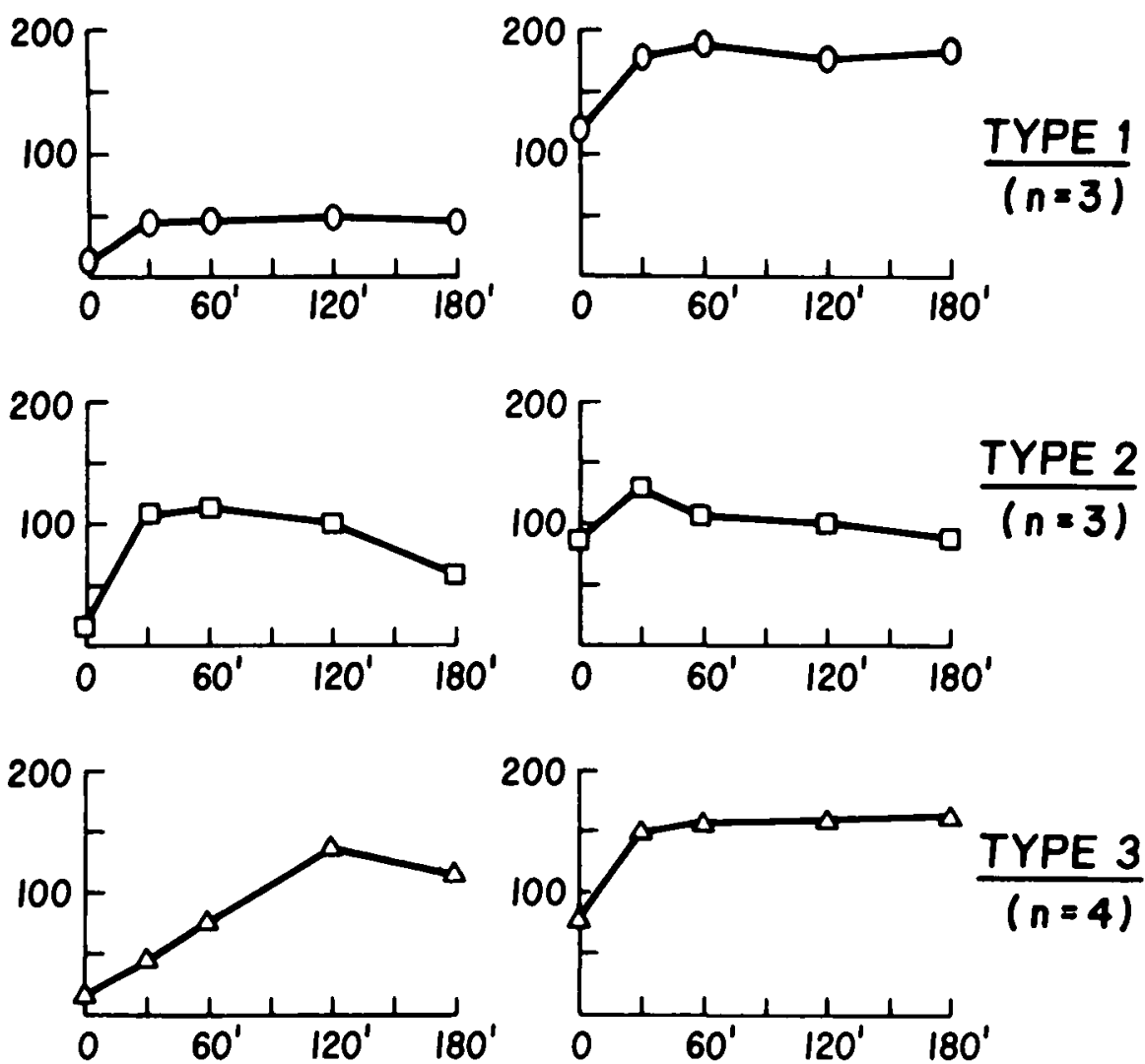

TIME (min)

Figure I - Insulin and blood glucose responses in Friedreich's ataxia to oral glucose load.

which is generally below $2 \%$. Although this is not a new finding, our studies confirm the presence of abnormal glucose metabolism in Friedreich's ataxia, independent of the severity or duration of illness.

The association of Friedreich's ataxia and diabetes is not a unique finding. Others have found increased diabetes with hereditary ataxias of different origins. Schalch et al. (1970) attributed the impaired glucose tolerance and marked hyperinsulinemia they found in ataxia telengiectasia to impaired hepatic function for which there was clinical and laboratory evidence in his subjects. Collis and Engel (1968) found an increased incidence of diabetes in amyotrophic lateral sclerosis, mus- cular dystrophy, late onset myopathy, myotonic dystrophy and chronic peripheral neuropathy. They found the severity of glucose intolerance was directly related to the degree of handicap and muscle wasting, and proposed that the impaired G.T.T. was caused by decreased muscle mass available to take up the glucose load. In this regard, Hewer and Robinson (1968) observed that their patients with ataxia/diabetes were severely disabled.

In our patients, there was no clinical or biochemical evidence of markedly impaired hepatic function although finer tests would be required to rule out this possibility. It is difficult to evaluate the argument that decreased muscle mass was the reason for the diabetes in our subjects, but the fact that the distribution of age and duration of disease in these subjects with both entities did not differ significantly from the total group of subjects makes this unlikely. The high incidence of hyperinsulinemia after a glucose load in the presence of normal or elevated fasting blood glucose levels would indicate either hypersecretion or failure of end-organ utilization, but base line (fasting) insulin levels were normal or low in all groups. Furthermore, as we did not find any evidence of hypoglycemia, it could be postulated that the high insulin levels were due to decreased activity at the site of utilization in the muscle or elsewhere. Whether this is due to deficiency of membrane tissue receptors for insulin - as has been reported in diabetic animals and humans - or whether it reflects a defect at the second messenger level or later metabolic control stages is an open question. However, these two hypotheses are amenable to experimental investigation which we are currently undertaking. One could also postulate the secretion of a biologically ineffective insulin, or decrease in breakdown of insulin in the liver, although, these hypotheses appear less probable.

In an interesting side-light to this study, which will be referred to elsewhere, we compared the verbal I.Q. of 10 typical Friedreich's ataxia patients with diabetes to that of 12 typical Friedreich's ataxia patients without this complication. The presence of diabetes was associated with significantly decreased verbal $1 . Q$. (mean 88.5 as compared to 99.7). Only $1 / 12$ patients (8\%) without diabetes had a I.Q. below 90 . whereas $5 / 10(50 \%)$ with diabetes were below that level. It is possible that abnormal glucose metabolism in these patients impairs global brain functionning as partially reflected by the I.Q. tests.

In conclusion, we can confirm that the incidence of diabetes (both clinical and chemical) is greater in patients with Friedreich's ataxia than in the general population, but this finding may not be specific to this 
type of ataxia. Furthermore, we have shown that most patients with ataxia have normal or low fasting insulin levels, but a hyperinsulinic response to a glucose load, as if the peripheral utilization of insulin were impaired.

\section{ACKNOWLEDGMENTS}

The studies reported in this paper were partially supported by l'Association Canadienne de l'Ataxie de Friedreich, la Fondation Jeanne-Mance and the Medical Research Council of Canada.

\section{REFERENCES}

ASHBY, D. W., and TWEEDY, P. S. (1953). Friedreich's ataxia combined with diabetes mellitus in sisters. Brit. Med. J., 1, 1418-1421.
COLLIS, W. J., and ENGEL, W. K. (1968). Glucose metabolism in five neuromuscular disorders. Neurology, 18, 915-925.

DANOWSKY, T.S. (1957). Diabetes mellitus with emphasis on children and young adults. Williams and Wilkins Co., Baltimore, pp. 140-165.

HEWER, R. L., and ROBINSON, N. (1968). Diabetes mellitus in Friedreich's ataxia. J. Neurol. Neurosurg. Psychiat., 31, 226-231.

IKKOS, D., and LUFT, R. (1957). On the intravenous glucose tolerance test. Acta Endocr., 25, 312-319.

JOFFE, B. I., SEGAL, I. and COOPER, W. (1968). Evolution of diabetes mellitus in cases of Friedreich's ataxia. J. Neurol. Neurosurg. and Psychiat., 36, 484-493.

JOFFE, B. I., SEGAL, I., and KELLER, P. (1970). Insulin levels in hereditary ataxias. N. Engl. J. Med., 283: 1410-1411.
PODOLSKY, S., POTHIER, A., and KRALL, L. P. (1964). Association of diabetes mellitus and Friedreich's ataxia. A study of two siblings. Arch. Intern. Med., 114, 533-537.

PODOLSKY, S., and SHEREMATA, W. A. (1970). Insulin-dependent diabetes mellitus and Friedreich's ataxia in siblings. Metabolism, 19, 555-561.

SCHALCH, D. S., McFARLIN, D. E., and BARLOW, M. H. (1970). An unusual form of diabetes mellitus in ataxia telangiectasia. N. Engl. J. Med., 282, 1396-1401.

SCHLESINGER, N. S. and K. GOLDSTEIN (1940). Friedreich's ataxia associated with diabetes mellitus. N.Y. State J. Med., 40, 415-423.

THOREN, C. (1962). Diabetes mellitus in Friedreich's ataxia. Acta Paediat., 51, suppl. 135, 239-247. 